УДК 631.365.22

(СС.Г. Панасюк, к.т.н., В.А. Сай, к.т.н., О.В. Денисюк Луцький національний технічний університет

\title{
ДОСЛІДЖЕННЯ РУХУ НАСІНИНИ СОНЯШНИКА У ВІДЦЕНТРОВОМУ ОБРУШУВАЧІ
}

У статті приведено результати дослідження руху насінини соняшника у відиентровому обрушувачі та впливу швидкості обертання диска на швидкість вильоту насінини з диска та часу ї̈ перебування на диску відиентрового обрушувача.

Постановка проблеми. На якість соняшникової олії впливають процеси, що відбуваються під час переробки насіння. Одним 3 основних та найскладніших завдань, яке постає перед виробниками, $є$ якісне обрушування насіння соняшника, яке полягає у руйнуванні оболонки та її відділення від ядра. Від того, наскільки ефективно пройде обрушування, залежить якість отриманої олії.

На процес обрушування в тій чи іншій мірі можуть впливати багато факторів, зокрема параметри обрушувача та властивості самого насіння. Тому необхідно знати, які саме фактори впливають на якість обрушування та вміти оперувати параметрами, що характеризують ці фактори.

Основна вимога при процесі обрушування ставиться власне до конструкції обрушуючої машини, яка повинна забезпечити отримання максимальної кількості цілих ядер та мінімальне утворення недорушу та олійного пилу.

Незважаючи на велику кількість обрушуючих машин та проведення досліджень для їхнього удосконалення, ще не створено такої установки, щоб забезпечувала бездоганну якість процесу обрушування.

Аналіз останніх досліджень та публікацій. Теоретичним дослідженням процесу обрушування насіння соняшника присвячені праці Л.І. Перевалова, А.В Попсуйшапки, Ф.Ф. Гладкого [2, 5], В.П. Забродіна [3], С.Д. Запорожченка [4] та ін.

Л.І. Переваловим, А.В Попсуйшапкою, Ф.Ф. Гладким запропоновано спосіб обрушування насіння соняшника 3 попереднім охолодженням та дотриманням температурних режимів обрушування [5]. С.Д Запорожченко провів моделювання руху насінини соняшника у відцентровій обрушуючій машині [4] та 
визначив характер зношення робочих поверхонь направляючих лопаток.

Аналіз проведених досліджень вказує на те, що найкраще використовувати для проведення якісного обрушування насіння соняшника відцентрові обрушуючі машини. Але залишається не повністю вивченим вплив кінематичних параметрів робочих органів відцентрового обрушувача на характер руху насінини соняшника в процесі обрушування.

Метою дослідження було виявлення впливу швидкості обертання диска на швидкість вильоту насінини з диска та часу іiі перебуванні на диску у відцентровому обрушувачі.

Результати дослідження. Зміна швидкості частинки у відцентровому середовищі диска обрушувача залежить від багатьох параметрів, одним 3 яких $\epsilon$ форма лопатей, яка визначається значенням кутів $\alpha$ та $\beta$. Залежно від числового значення кутів $\beta$ розрізняють три форми лопатей: загнуті вперед $\left(\beta>90^{\circ}\right)$ (рис. 1 , поз. 1); радіальні $\left(\beta=90^{\circ}\right)$ (рис. 1 , поз. 2); загнуті назад $\left(\beta<90^{\circ}\right)$ (рис. 1, поз. 3). Для кожної форми (профілю) лопатей буде характерним певний трикутник швидкостей при вильоті насінини соняшника із диска.

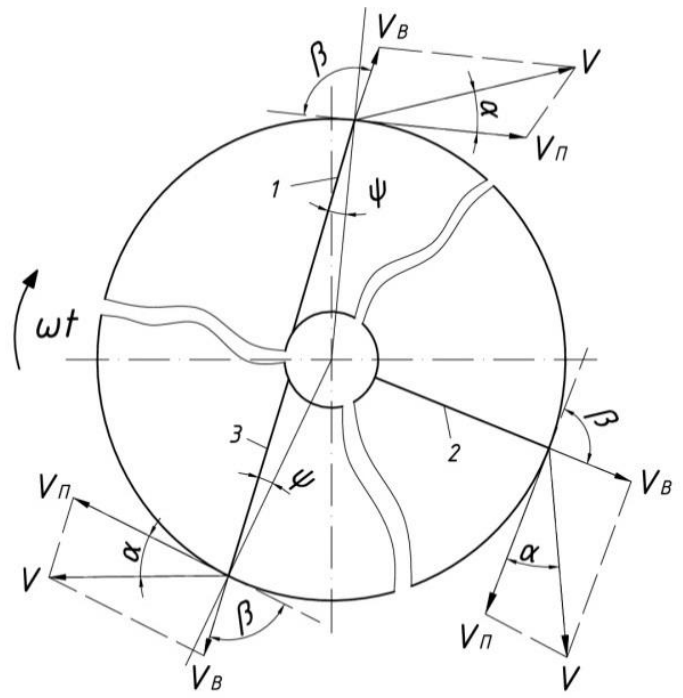

Рис. 1 - Схема швидкостей насінини соняшника при вильоті з диска 3 різними формами лопатей: 1 - загнута назад; 2 - радіальна; 3 загнута вперед 
Проаналізувавши схему, бачимо що вектор абсолютної швидкості польоту насінини при виході із диска більший при більшому куті $\beta$, що відповідає профілю лопаті, яка загнута вперед (рис.1, поз. 1). Звідси теоретична швидкість вильоту насінини при контакті 3 лопаттю із таким профілем буде найбільшою. Механічний опір, який виникає при відриві насінини від лопаті, через дію відцентрових сил збільшує напруження в матеріалі робочого диска, що в свою чергу потребує використання більш якісних сплавів металів.

Диск із радіальними лопатями створює певну середню теоретичну швидкість вильоту насінини, відповідно диск із відігнутими лопатями назад створює найменшу теоретичну швидкість вильоту.

Таким чином, при збільшені кута $\alpha$ зменшується швидкість $V_{\Pi}$, що призводить до зменшення величини енергії для виконання роботи $A$, яка затрачається на обрушення. При цьому питома кількість сходження насінин за одиницю часу буде зростати.

Також потрібно відмітити, що збільшення кута $\alpha$ призводить до більшого відхилення вектора абсолютної швидкості $V$ від радіального напрямку вперед по напряму обертання, а, отже зменшення швидкості $V_{\text {I }}$ і збільшення енергії для виконання роботи $A$. Але при цьому зменшиться радіальна складова абсолютної швидкості $V_{B}$ і збільшується тангенціальна складова $V_{I}$, тобто зменшується питома кількість сходження насінин 3 диска.

Розглянемо схему вильоту насінини соняшника при взаємодії з лопаттю, загнутою вперед, так як у цьому випадку швидкість вильоту частинки найбільша.

Насінини, які потрапили на диск, що обертається, знаходяться в полі дії таких сил: відцентрова сила, сила тяжіння та Коріолісова сила.

Розглянемо одну насінину, яка знаходиться на диску, який обертається 3 постійною кутовою швидкістю $\omega t$ (рис. 2). Ця насінина знаходиться на певній відстані $R_{n}$ від осі обертання $O$. Вісь $O x y z$ - рухома, але жорстко зв'язана 3 диском, вісь $O x_{1} y_{1} z_{1}-$ нерухома відносно центра $O$ [6].

В якості відносного руху приймемо рух насінини по лопаті диска. При відносному русі на частинку діють: сила ваги $\vec{P}$, нормальна реакція зі сторони диска $\overrightarrow{N_{1}}$, нормальна реакція зі 
сторони лопаті $\overrightarrow{N_{2}}$, сила тертя, що виникає при ковзанні зернини по лопаті $\overrightarrow{F_{T 1}}$, сила тертя, що виникає при ковзанні зернини по диску $\overrightarrow{F_{T 2}}$, переносна сила інерції $\overrightarrow{F_{e}}$, Коріолісова сила інерції $\overrightarrow{F_{K}}$

3 основного рівняння динаміки загальне векторне рівняння відносного руху насінини, що розглядається має вигляд:

$$
m \cdot \overrightarrow{a_{r}}=\vec{P}+\overrightarrow{N_{1}}+\overrightarrow{N_{2}}+\overrightarrow{F_{T 1}}+\overrightarrow{F_{T 2}}+\overrightarrow{F_{e}}+\overrightarrow{F_{K}},
$$

Проектуємо рівняння (1) на Декартові осі координат $O x y z$ . Отримаємо диференціальне рівняння відносного руху насінини в проекціях на ці осі:

$$
\left\{\begin{array}{l}
m x^{\prime \prime}=F_{e} \cdot \cos \psi-F_{T 1}-F_{T 2} \\
m y^{\prime \prime}=F_{e} \cdot \sin \psi+F_{K}-N_{2}, \\
m z^{\prime \prime}=P-N_{1}
\end{array},\right.
$$

де $\psi$ - кут між дотичною до лопаті та радіусом, проведеним через центр диска.

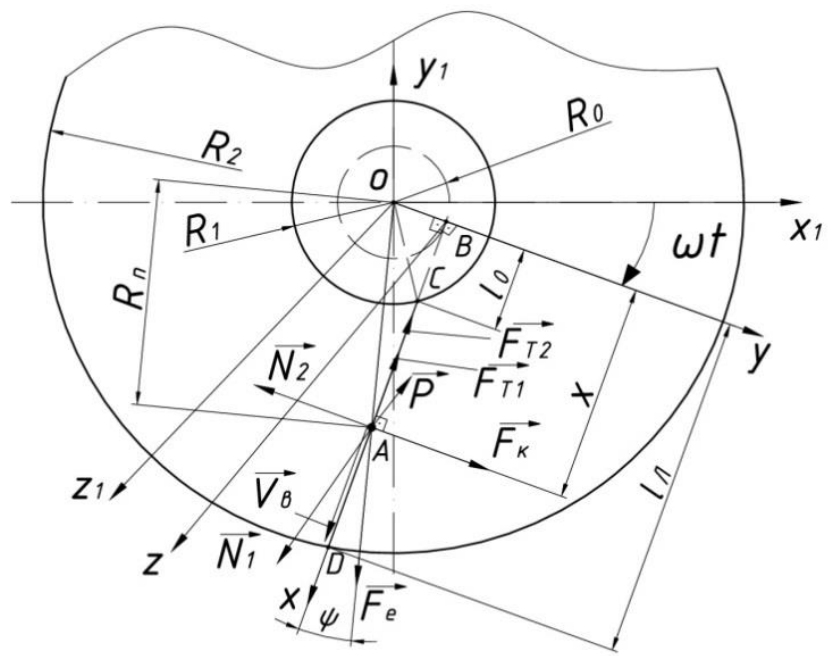

Рис. 2 - Схема сил, що діють на насінину в горизонтальній площині, та геометричні характеристики диска

Так як рух насінини відносно вісі $O z$ обмежено диском, то рівнодіюча сила рівна нулю: 


$$
m z^{\prime \prime}=0
$$

Отже з врахуванням рівняння (3):

$$
P=N_{1}=m \cdot g ;
$$

де $m$ - маса насінини, г;

$g$ - прискорення вільного падіння ( $\left.g=9,81 \mathrm{~m} / \mathrm{c}^{2}\right)$.

Рух зернини відносно вісі $O y$ обмежено лопаттю диска, і тому рівнодійна сила, яка діє на неї під час руху, буде рівна нулю:

$$
m y^{\prime \prime}=0 \text {; }
$$

Отже враховуючи рівняння (2) і (5) отримаємо:

$$
F_{e} \sin \psi+F_{K}-N_{2}=0
$$

3 рівняння (6) знайдемо $N_{2}$ :

$$
N_{2}=F_{e} \cdot \sin \psi+F_{K}
$$

Коріолісова сила інерції визначається як:

$$
F_{K}=2 m \cdot \omega \cdot V_{s} \cdot \sin 90^{\circ}=2 m \cdot \omega \cdot V_{\theta},
$$

де $\omega$ - кутова швидкість диска, рад/с;

$V_{\text {в }}$ - відносна швидкість насінини, м/с.

Переносна сила інерції буде:

$$
F_{e}=m \cdot \omega^{2} \cdot R_{n}
$$

де $R_{n}$ - відстань від осі обертання до насінини, м.

Підставивши в рівняння (7) залежності (8), (9) отримаємо:

$$
N_{2}=m \cdot \omega^{2} \cdot R_{n} \cdot \sin \psi+2 \cdot m \cdot \omega \cdot V_{s} ;
$$

Відповідно до гіпотези Амонтона-Кулона сила сухого тертя прямо пропорційна величині сили нормального тиску і спрямована в бік, протилежному руху насінини. Звідси сили тертя $\overrightarrow{F_{T 1}}$ та $\overrightarrow{F_{T 2}}$ визначаються за наступними формулами:

$$
\begin{gathered}
F_{T 1}=f_{1} \cdot N_{1} ; \\
F_{T 2}=f_{2} \cdot N_{2} .
\end{gathered}
$$

де $f_{1}$ та $f_{2}$ - відповідно коефіцієнти тертя ковзання по сталевому диску та лопаті ( для матеріалу насіння-сталь $f_{1}=f_{2}=f$ ).

Підставимо отримане значення рівнянь (4), (7) в рівняння (11), (12) отримаємо:

$$
\begin{gathered}
F_{T 1}=f \cdot m \cdot g ; \\
F_{T 2}=f \cdot m \cdot \omega^{2} \cdot R_{n} \cdot \sin \psi+2 \cdot f \cdot m \cdot \omega \cdot V_{s} .
\end{gathered}
$$


Тут відносна швидкість дорівнює першій похідній від переміщення: $V_{\theta}=x^{\prime}$.

Підставивши отримані значення у векторне рівняння (1) та врахувавши рівності (8) - (14), отримаємо диференціальне рівняння відносного руху матеріальної точки по вісі $O x$ :

$$
m x^{\prime \prime}=m \omega^{2} R_{n} \cos \psi-f m g-f m \omega^{2} R_{n} \sin \psi-2 f m \omega x^{\prime} ;
$$

Проведемо зведення диференційного рівняння (15), поділивши на $m$ :

$$
x^{\prime \prime}=\omega^{2} R_{n} \cos \psi-f g-f \omega^{2} R_{n} \sin \psi-2 f \omega x^{\prime} ;
$$

3 прямокутного трикутника $\triangle A O B$ (рис 2) визначимо:

$$
R_{n}=\sqrt{R_{0}^{2}+x^{2}}
$$

де $x$ - шлях, пройдений насіниною по лопаті диска;

$R_{0}$ - радіус дотичної до лопаті, м.

Із властивостей прямокутного трикутника $\triangle A O B$ отримаємо:

$$
\begin{aligned}
& \cos \psi=\frac{x}{R_{n}}=\frac{x}{\sqrt{R_{0}^{2}+x^{2}}} ; \\
& \sin \psi=\frac{R_{0}}{R_{n}}=\frac{R_{0}}{\sqrt{R_{0}^{2}+x^{2}}} ;
\end{aligned}
$$

Підставивши формули (18), (19) в диференціальне рівняння (16) отримаємо:

$$
x^{\prime \prime}=\omega^{2} \sqrt{R_{0}^{2}+x^{2}} \frac{x}{\sqrt{R_{0}^{2}+x^{2}}}-f g-f \omega^{2} \sqrt{R_{0}^{2}+x^{2}} \frac{R_{0}}{\sqrt{R_{0}^{2}+x^{2}}}-2 f \omega x^{\prime}
$$

Звівши рівняння (20), будемо мати:

$$
x^{\prime \prime}=\omega^{2} x-f g-f \omega^{2} R_{0}-2 f \omega x^{\prime} ;
$$

Отримане рівняння (21) характеризує відносний рух насінини в робочому органі відцентрового обрушувача.

Для знаходження початкової швидкості насінини соняшника при вильоті 3 диска скористаємося диференційним рівнянням (21), яке являє собою неоднорідне лінійне диференційне рівняння другого порядку. Для початку здійснимо перегрупування членів цього рівняння

$$
x^{\prime \prime}+2 f \omega x^{\prime}-\omega^{2} x=-f g-f \omega^{2} R_{0} ;
$$


Для отриманого диференційного рівняння (22) з постійною правою частиною, спільний інтеграл буде:

$$
x=x_{0}+x_{1} ;
$$

де $x_{0}-$ загальне рішення лінійного однорідного диференційного рівняння;

$x_{1}$ - часткове рішення.

Для виразу (22) характеристичне рівняння буде мати вигляд:

$$
\lambda^{2}+2 \cdot f \cdot \omega \cdot \lambda-\omega^{2}=0
$$

Звідси:

$$
\begin{gathered}
\lambda_{1}=\omega \cdot\left(\sqrt{1+f^{2}}-f\right), \\
\lambda_{2}=-\omega \cdot\left(\sqrt{1+f^{2}}+f\right) ;
\end{gathered}
$$

Підставивши постійні величини $c_{1}$ i $c_{2}$ отримаємо загальний розв'язок лінійного однорідного диференційного рівняння:

$$
x_{0}=c_{1} \cdot e^{\lambda_{1} \cdot t}+c_{2} \cdot e^{\lambda_{2} \cdot t} ;
$$

де $t$ - час перебування насінини на диску при русі по лопаті, с;

$c_{1}, \lambda_{1}, c_{2}, \lambda_{2}-$ постійні величини.

Часткове рішення $x_{1}$ знайдемо наступним чином:

$$
x_{1}=\frac{f g+f \omega^{2} R_{0}}{\omega^{2}}=f \cdot R_{0}+\frac{f \cdot g}{\omega^{2}} ;
$$

Підставляючи рівняння (27) i (28) в рівняння

отримаємо значення пройденого шляху насінини по лопаті диска:

$$
x=c_{1} \cdot e^{\lambda_{1} \cdot t}+c_{2} \cdot e^{\lambda_{2} \cdot t}+f \cdot R_{0}+\frac{f \cdot g}{\omega^{2}} ;
$$

Визначимо постійні величини $c_{1}$ i $c_{2} \quad 3$ врахуванням початкових умов руху, тобто при: $t=t_{0}=0 \quad \mathrm{c}$, $x=x_{0}=l_{0}=\sqrt{R_{1}^{2}-R_{0}^{2}} \mathrm{M}, \quad$ де $\quad 3 \quad \triangle C O B \quad l_{0}=O B$, $x^{\prime}=x_{0}^{\prime}=l_{0}^{\prime}=\xi \cdot \omega \cdot R_{1} \quad$ м/с, де $\xi=0,8 \quad-\quad$ коефіцієнт, який характеризує умови зчеплення матеріалу з диском.

Для знаходження відносної швидкості руху по лопаті диска проводимо диференціювання рівняння (29) по часу $t$ з врахуванням рівнянь (25), (26):

$$
x_{0}^{\prime}=c_{1} \cdot \lambda_{1}+c_{2} \cdot \lambda_{2}
$$


Складаємо систему:

$$
\left\{\begin{array}{l}
x_{0}=\sqrt{R_{1}^{2}-R_{0}^{2}}=c_{1}+c_{2}+f \cdot R_{0}+\frac{f \cdot g}{\omega^{2}}, \\
x_{0}^{\prime}=\xi \cdot \omega \cdot R_{1}=c_{1} \cdot \lambda_{1}+c_{2} \cdot \lambda_{2}
\end{array}\right.
$$

Система (31) містить два невідомих $c_{1}$ i $c_{2}$. Із першого рівняння системи отримаємо:

$$
c_{1}=\sqrt{R_{1}^{2}-R_{0}^{2}}-c_{2}-f \cdot R_{0}-\frac{f \cdot g}{\omega^{2}} ;
$$

Підставивши в друге рівняння системи значення $c_{1}$ та звівши його отримаємо наступний вираз:

$$
c_{2}=\sqrt{R_{1}^{2}-R_{0}^{2}}-f \cdot R_{0}-\frac{f \cdot g}{\omega^{2}}-\frac{\xi \cdot \omega \cdot R_{1}}{\lambda_{1}} ;
$$

Підставивши значення рівняння (33) в рівняння отримаємо:

$$
c_{1}=-\frac{\xi \cdot \omega \cdot R_{1}}{\lambda_{1}}
$$

Підставивши значення невідомих $c_{1}$ і $c_{2}$ в рівняння (29) отримаємо остаточне рівняння руху насінини по лопаті диска, що характеризує розміщення насінини в певний момент часу на лопаті диска:

$$
x=-\frac{\xi \cdot \omega \cdot R_{1}}{\lambda_{1}} \cdot e^{\lambda_{1} \cdot t}+\left(\sqrt{R_{1}^{2}-R_{0}^{2}}-f \cdot R_{0}-\frac{f \cdot g}{\omega^{2}}-\frac{\xi \cdot \omega \cdot R_{1}}{\lambda_{1}}\right) \cdot e^{\lambda_{2} \cdot t}+f \cdot R_{0}+\frac{f \cdot g}{\omega^{2}} ;
$$

Для знаходження відносної швидкості вильоту насінини із лопаті диска в момент часу проведемо диференціювання рівняння (35) по часу $t$ :

$$
x^{\prime}=-\xi \cdot \omega \cdot R_{1} \cdot e^{\lambda_{1} \cdot t}+\left(\sqrt{R_{1}^{2}-R_{0}^{2}}-f \cdot R_{0}-\frac{f \cdot g}{\omega^{2}}-\frac{\xi \cdot \omega \cdot R_{1}}{\lambda_{1}}\right) \cdot \lambda_{2} \cdot e^{\lambda_{2} \cdot t} ;
$$

Аналізуючи рівняння (35), (36) можна відмітити одну особливість, що в жодному із цих рівнянь не враховується маса зернин. Із цього слідує, що закон відносності руху не змінюється для зерна різних розмірів і що зерно, різне за масою, рухається по диску з однаковою швидкістю. 
Таким чином, всі зерна, що вилітають $з$ лопаті диска, мають однакову швидкість. Така властивість дозволяє організувати потік насіння на лопаті диска в одну нитку, що запобігає зіткненню цих насінин при польоті від ротора до деки. Завдяки цьому у відцентровому обрушувачі не повинно залишатися недообрушених зернин.

Можливість обмеження руху насіння соняшника по диску в одну нитку на практиці здійснюється неповністю. Це викликане тим, що при вираженні диференціального рівняння руху зерен коефіцієнт їх тертя по поверхні диска приймається постійним, що справедливо тільки при однаковій вологості насінин. В зерновій суміші ж вологість насінин може різнитися, і тому спостерігається порушення руху насінин в одну нитку [3].

Для знаходження часу перебування насінини на лопатці диска $t_{K}$ необхідно визначити довжину лопаті $x$ iз прямокутного трикутника $\triangle D O B$, що становить $x=l_{\pi}=\sqrt{R_{2}^{2}-R_{0}^{2}}$ та провести обчислення рівняння (35):

Підставляючи значення $t_{K}$ в рівняння (36) визначимо $x^{\prime}=V_{n}$ на кінці лопаті диска.

Для полегшення обчислення диференційного рівняння (21) та визначення відносної швидкості $V_{n}$ та часу перебування використаємо програмний пакет Maple 7.0. Проведення досліджень параметрів руху частинки проводилося при фіксованому значенні параметрів конструкції відцентрового обрушувача: $R_{0}=0,05$ м, $R_{1}=0,075 \mathrm{M}, \quad R_{2}=0,375 \mathrm{M} . \quad$ У $\quad$ результаті теоретичного дослідження отримано залежність початкової відносної швидкості вильоту насінини соняшника $V_{n}$ від частоти обертання диска $n$ (рис. 3) та часу перебування насінини на лопаті диска $t_{K}$ від частоти обертання диска $n$ (рис 4). 


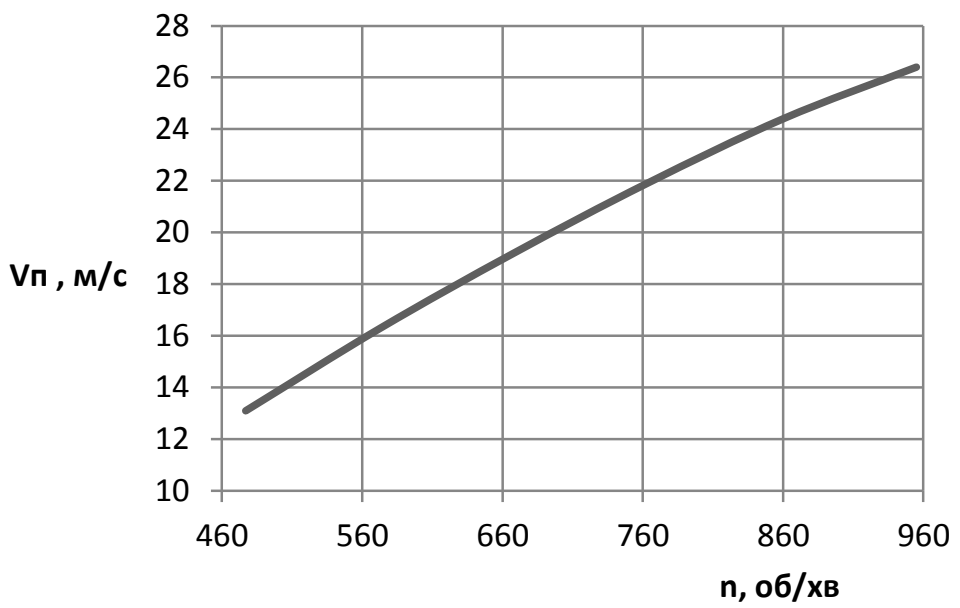

Рис. 3 - Залежність відносної швидкості вильоту насінини соняшника від частоти обертання диска

Із отриманого графіка (рис. 3) можна зробити висновок, що зі збільшенням частоти обертання диска збільшується відносна швидкість вильоту зернини із лопаті диска.

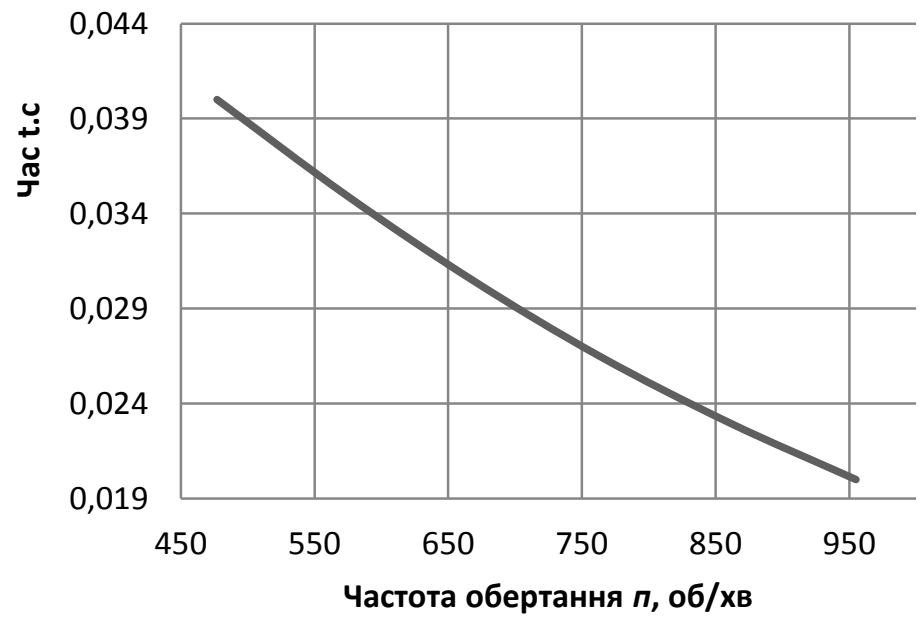

Рис. 4 - Залежність часу перебування насінини соняшника на лопаті від частоти обертання диска 
Отриманий графік (рис. 4) показує, що зі збільшенням частоти обертання диска зменшується час перебування зернини на лопаті диска.

Висновоки. Проведені дослідження дозволили виявити вплив швидкості обертання диска на швидкість вильоту насінини 3 диска та часу іiі перебуванні на диску відцентрового обрушувача.

\section{Література}

1. Бовсуновський В.М., Лук'янець В.О. Установка для лущення насіння олійних культур // Матеріали IV міжнародної науково-практичної конференції "Динаміка наукових досліджень2005". Том 45. Сільське господарство. - Дніпропетровськ: Наука і освіта, 2005. - С. 32-33.

2. Влияние условий обрушивания высокомасличного подсолнечника на переход восков в масло / Л.І. Перевалов, С.Л. Тесленко, А.А. Нетреба // Восточно-Европейский журнал передовых технологий ISSN 1729-3774. - 2014 - Т.67, № 1. C. $41-47$.

3. Забродин В.П. Анализ взаимодействия частиц с лопаткой наружного диска распределительного рабочего органа [Текст] // Совершенствование технологических процессов и конструкций сельскохозяйственных машин. - Краснодар, 1989. - Вып. 294(322). - C. 84-91.

4. Запорожченко С.Д. Совершенствование и моделирование процесса центробежного обрушивания масличных семян: диссертация па соискание ученой степени кандидата технических наук: 05.018.2012 / Запорожченко С. Д. - К., 2012. - 114 с.

5. Павловський М. А. Теоретична механіка: Підручник. - К.: Техніка, 2002. -512 с.: іл. 